Published in final edited form as:

Sci Commun. 2006 September ; 28(1): 122-142.

\title{
Brain Imaging:
}

\section{A Decade of Coverage in the Print Media}

Eric Racine

Institut de Recherches Cliniques de Montréal, Québec, Canada

Ofek Bar-llan

Stanford University, Palo Alto, California, Dominican University of California, San Rafael

Judy Illes

Stanford University, Palo Alto, California

\section{Abstract}

Advances in neuroscience are increasingly intersecting with issues of ethical, legal, and social interest. This study is an analysis of press coverage of an advanced technology for brain imaging, functional magnetic resonance imaging, that has gained significant public visibility over the past ten years. Discussion of issues of scientific validity and interpretation dominated over ethical content in both the popular and specialized press. Coverage of research on higher order cognitive phenomena specifically attributed broad personal and societal meaning to neuroimages. The authors conclude that neuroscience provides an ideal model for exploring science communication and ethics in a multicultural context.

\section{Keywords}

neuroethics; functional magnetic resonance imaging; press; neuroscience; content analysis; bioethics

\begin{abstract}
Advances in neuroscience are intersecting with ethical, legal, and social issues. Some issues concern clinical applications such as the early diagnosis of disease, while others relate to the growing number of studies using frontier neurotechnologies such as functional magnetic resonance imaging (fMRI) of social behaviors. Here, we present a study on how fMRI, one model of neurotechnology that has diffused rapidly in the research environment and gained substantial visibility, has been covered in the print media. Drawing on lessons learned from press coverage of other scientific domains, we examined the complexity of communication of brain findings and the need for their consideration in a multicultural context.

In the past, press coverage of genetics and genomics has brought ethical, social, and legal issues to the forefront. Scholars of bioethics, social sciences, and law, for example, have investigated informed consent, risks of "geneti-cization," and breaches of confidentiality extensively. Vast interdisciplinary programs in numerous countries have addressed these issues and others. Scholars of science communication and other social scientists have played an important role in disseminating the information resulting from this research. For more than two decades, they
\end{abstract}

\footnotetext{
Authors'Note: This research was supported by The Greenwall Foundation, National Institutes of Health/National Institute of Neurological Disorders and Stroke grant R01 \#NS045831, and Fonds Québécois de la Recherche sur la Société et la Culture and Social Sciences and Humanities Research Council. We extend our thanks to Dr. Charles Jennings for inspiring this project and to Dr. Scott W. Atlas, Dr. Thomas A. Raffin, Dr. Pamela Schraedley-Desmond, Marisa Gallo, and Sarah Waldman. Correspondence concerning this article should be addressed to Judy Illes, Program in Neuroethics, Stanford Center for Biomedical Ethics and Department of Radiology, Stanford University, 701 Welch Road, Suite A1105, Palo Alto, CA 94304-5748; phone: (650) 724-6393; fax: (650) 725-6131; e-mail: illes@stanford.edu.
} 
have attended to the issues of the new genetics, and their contributions have been instrumental in broadening the debate and in bringing attention to marginal points of views (Conrad and Gabe 1999). The outcome is that the genomics community has a solid base of knowledge and discussion for informed and responsible science communication (Cardinal et al. 2003; Condit 2001; Condit, Parrott, and O'Grady 2000; Racine 2003).

Stem-cell research and embryo research have also been a focus of communication research, albeit on a smaller scale (Mulkay 1994; Williams, Kitzinger, and Henderson 2003). The academic community and the larger public are probably less aware, however, that similar issues are pending in contemporary neuroscience research. In fact, some argue that far more than our genome, the brain constitutes an integral part of our concept of the self (Greely 2002; Kennedy 2003; Mauron 2003). Consequently, we may speak of a "neuroscience revolution" (Wolpe 2002). In this article, we provide background to support these claims and explore them through the lens of press coverage of functional neuroimaging studies.

\section{Contemporary Neuroscience}

The study of the nervous system has been an enduring medical research tradition led by preeminent physicians and researchers. Contemporary neuroscience feeds on this tradition and draws on a vast and interdisciplinary history to study the nervous system. Subspecialties of neuroscience include neurophysiology, which studies the detailed electrical activity of neurons and other neuronal structure; neurobiology, which focuses on the molecular and cellular understanding of the nervous system; and cognitive neuroscience, which tries to understand correlations between cognitive phenomena and biological patterns. These may be measured as electrical signals using electroencephalography, for example, as blood flow using positron emission tomography or single photon emission tomography or as changing blood oxygenation levels in stimulus-response paradigms using fMRI, our focus here. Resulting information from these different imaging modalities is sometimes complementary; at other times, it may provide competing explanations of similar phenomena. Nevertheless, the integration of knowledge stemming from multiple levels of inquiry has yielded new insights into neurological and psychiatric diseases.

The study of human brain function has been greatly facilitated by neuroimaging techniques that have made possible research on increasingly complex cognitive phenomena, including emotions, personality traits, and real-world behaviors. fMRI is of particular interest because of its noninvasiveness (therefore allowing a greater degree of repeatability than before) and widespread use by the research community. Between 1991, when the results of the technique were first reported, and 2004, tens of thousands of studies were cited in PubMed (Raichle 2004). There has also been a steady expansion of studies with social and policy implications (Illes, Kirschen, and Gabrieli 2003). Among this research are studies specifically of thought processes, emotions, racial attitudes, personality traits, religious experience, deception, and moral reasoning (Illes, Racine, and Kirschen 2005).

Research results are already permeating the public sphere. Neuroimaging data have been admitted in courts, ${ }^{1}$ and in one case, a homicide conviction was reversed because the state failed to provide brain scans (People v. Weinstein 1992). Studies of consumer preferences using fMRI to inform marketing strategies_-"neuromarketing"- have been discussed by the neuroscience community and the wider public ("Brain Scam?" 2004; "Open Your Mind"

\footnotetext{
${ }^{1}$ Some studies have investigated neuronal differences between false and truthful memory (Schacter, Buckner, and Koutstaal 1998) or deception (Langleben et al. 2002), while others focus on neural mechanisms involved in the active suppression of memory (Anderson et al. 2004). Electroencephalographically derived "brain fingerprinting" has been recently promoted as a tool for determining whether an individual is in possession of certain knowledge of a crime (Farwell and Smith 2001). The brain exhibits specific responses when a person recognizes significant information, such as crime scene details (Farwell and Smith 2001).
} 
2002). As the power of imaging technologies increases, novel studies may yield novel applications such as mind reading (Ross 2003). Some new imaging technologies, such as functional near-infrared imaging of the brain, promise to deliver inexpensive, reliable, and portable imaging neurotechnologies that are as accurate as the current costly and equipmentcumbersome functional imaging based on magnetic resonance technology. For example, a wearable headband functional near-infrared tool is being developed to investigate real-world behaviors, with possible uses such as lie detection (Izzetoglu et al. 2004). Hence, as the power of brain imaging technologies increases, so will the magnitude of the issues it raises.

\section{A Convergence of the New Field of Neuroethics and Science Communication}

Debate on these studies and their projected applications is starting, mainly under the impetus of a new interdisciplinary field, neuroethics, that specifically focuses on the ethical implications of contemporary neuroscience (Illes and Raffin 2002; Moreno 2003). Neuroethics includes both the "ethics of neuroscience" (i.e., ethical issues raised by emerging neurotechnology such as neuropharmaceutical enhancement) and the "neuroscience of ethics" (i.e., understanding moral reasoning with the help of neuroscience methods; Roskies 2002). Given its expanding use and related challenges, fMRI represents a model for discussing implications of modern neurotechnologies. In this context, media coverage constitutes one important pathway to assess what the issues surrounding fMRI are and how the technology is portrayed outside the peerreviewed literature. At this point in the neuroethics debate, press analysis constitutes an invaluable source of information for neuroscientists, social scientists, policy makers, and bioethicists. To our knowledge, apart from a theoretical article on this topic that we published (Racine, Bar-Ilan, and Illes 2005), this exploratory study was the first study of how fMRI has been featured in the print media. It was a detailed examination of the characteristics of the coverage to date and an outlook on ethical and social challenges associated with brain imaging introduced by the press.

\section{Methods}

\section{Sample}

We generated the sample for this work using LexisNexis Academic, a database consisting of full-text news, business, and law resources. We searched for English-language articles from January 1, 1991 (Illes, Kirschen, and Gabrieli 2003), to June 1, 2004, using the "Guided News Search" with the keywords "neuro* AND imaging" and "functional magnetic resonance imaging" or "fMRI." The following news categories as defined by the LexisNexis Academic database were searched in headlines, lead paragraphs, and terms: general news (major newspapers), general news (magazines and journals), medical news (medical and health news), university news (The Chronicle of Higher Education, University Wire), and legal news. After all the articles $(N=442)$ were gathered, we examined them for relevance and removed the many duplicates arising from the frequent republication of articles. Individual articles were the sampling units, sorted according to whether they originated in general newspapers such as the New York Times and news magazines such as Newsweek or in specialized medical and science magazines such as Biotech Week and Medical Imaging Week.

\section{Coding}

Two independent coders (Racine and Bar-Ilan) analyzed all articles according to a detailed coding sheet. The units of analysis were the individual codes. Key codes were derived through an inductive process (Neuendorf 2002) in which previously used coding categories for content analysis of genomics research (Racine et al. 2006) were refined and adjusted to the context of neuroimaging research. Modifications included the addition of epistemological challenges and a refinement of the ethical issues section to take into account the specifics of fMRI. In addition, 
some new codes, such as target cohort and levels of explanation (simple or detailed), were added to the genomic coding scheme. This process culminated in the creation of a complete coding guide in which definitions for codes as well as instructions and examples were featured. Coders were trained to apply this coding system through a series of practice runs. A reliability pretest was conducted to ensure consistency and reliability as well as training adequacy. Table 1 presents details on the codes used for this study.

We also performed independent intercoder reliability tests on a randomly selected subsample of twenty-five articles. Results for reliability were calculated in terms of percentage agreement for the twenty-two $\operatorname{codes}^{2}$ (Table 1). A single code, "diffusion of technology," had a percentage agreement below .70 and was dropped out to ensure sufficient data reliability and reproducibility for this exploratory study.

\section{Data Analysis}

We used descriptive statistics to characterize the composition and properties of the sample and the chi-square statistic to test for main effects $(p<.05)$ between general and specialized sources and between health research and non-health-related research. In the comparison between general and specialized sources, codes for balanced and critical tone were combined because figures were individually too small for meaningful statistical comparison.

This exception was justified inasmuch as it provided results for uncritical articles featuring no scientific or ethical concerns, on the one hand, and articles presenting at least one scientific or ethical issue, on the other hand. We used the qualitative features of the data to elaborate on scientific and ethical issues and to illustrate salient points.

\section{Results}

\section{General Sample Characteristics}

Our search returned 132 unique articles appearing in the press between 1994 and 2004, none having been found prior to 1994. Seventy-nine articles (60 percent) represented general source articles, and 53 articles ( 40 percent) represented specialized sources. When applicable, results for both types of press are presented to provide further analytic insight.

\section{Quantitative Analyses}

Focus of the research and level of technical detail-The majority of articles featured research on adults ( $n=111,84$ percent). The minority presented research on school-aged children and adolescents ( $n=19,14$ percent), on the aging $(n=4,3$ percent), and on infants $(n=3,2$ percent $)$. Nine articles ( 7 percent $)$ discussed animal studies.

We found no explanation of the technical details of fMRI in the majority of articles ( $n=89$, 67 percent), simplified explanations in twenty-two articles (17 percent), and more detailed information in twenty-one articles (16 percent). An example of a simple explanation is as follows:

\footnotetext{
${ }^{2}$ The use of a reliability measure that takes into account chance agreements, such as Cohen's $\kappa$ or Krippendorff's $\alpha$, was considered. Unfortunately, the application of these measures to our reliability scores transformed high agreement into low $\kappa$. This is caused by the fact that these measures imply that expected values for agreement should depend on marginal totals. In this study, because we used mostly nonexclusive coding categories with individually low occurrence, we were subject to the disadvantage of the assumptions built into chance correction measures. Feinstein and Cicchetti (1990) previously demonstrated the effect of highly symmetrical imbalances (i.e., when $f_{1}>f_{2}$ ). The implications of this demonstration are sometimes underappreciated in the literature on press content analysis. In the case in which prevalence is unknown (such as in our case), there is no effective way to correct for the discrepancy between the symmetrical imbalance between $(0,0)$ scores and $(1,1)$ scores. We therefore believe that percentage agreement, with its shortcomings that we acknowledge, better reflects the reliability of the coding for this study given the assumptions of current chance correction reliability measures.
} 
Ogawa's research focused on certain magnetic changes that occur in blood hemoglobin when it binds to oxygen. This use of a physiologically dependent signal has contributed greatly to the development of technology for creating images of the functioning of the human body, particularly the brain. ("2003 Japan Prizes" 2003, 10)

Health-related and non-health-related research-Health-related research was featured in roughly a third of the articles $(n=46,35$ percent) and non-health-related research in 58 articles (44 percent). ${ }^{3}$ One-fifth of the articles $(n=27,20$ percent) presented both types of research.

Coverage of health-related research featured neurodegenerative diseases such as Alzheimer's and Parkinson's diseases ( $n=15,11$ percent) and psychiatric conditions such as depression and schizophrenia $(n=15,11$ percent $)$.

Coverage of non-health-related research focused principally on higher order cognitive systems such as decision making and motivation ( $n=42,32$ percent), other cognitive behaviors that have emotional and potential social impacts ( $n=33,25$ percent), and basic cognitive systems such as attention and memory. Integrative sensory systems (e.g., visual perception), basic sensory systems (e.g., vision), and motor systems were of a lesser focus.

Practical prospects and benefits of research-Prospective health-related benefits of fMRI were featured in half of the articles ( $n=65,49$ percent) and non-health-related prospects in many fewer ( $n=17,13$ percent). Health-related prospects were principally linked to hopes of better treatment ( $n=39,30$ percent) or diagnosis $(n=28,21$ percent). Health intervention monitoring was also featured in a small number of articles $(n=12,9$ percent). With respect to non-health-related benefits, a small number of articles ( $n=5,4$ percent) featured early childhood intervention learning and teaching improvements. Other equally infrequent benefits (2 percent each) were neuromarketing, lie detection, and technical improvements to fMRI.

Benefits were often highlighted in news headlines or lead paragraphs, even if findings suggesting them were tentative.

Tone of articles-The vast majority of the articles $(n=104,79$ percent $)$ were uncritical in tone, whereas twenty-eight (21 percent) were balanced or critical (Table $2 ; \chi^{2}=5.184, p=$. 023). The uncritical articles ranged from optimistic to neutral reporting of fMRI.

Articles that featured health-related research, non-health-related research, or both yielded significant differences in terms of tone. Of articles presenting health-related research, four $(9$ percent) contained references to an ethical risk; this increased to fourteen of fifty-eight articles (24 percent) for non-health-related research and to eleven of twenty-seven articles (41 percent) presenting both $\left(\chi^{2}=10.378, p=.006\right)$. Health-related research articles were less critical than articles featuring non-health-related research, but articles containing both types of research were more critical $\left(\chi^{2}=10.635, p=.031\right)$ (Table 3$)$.

Scientific and ethical concerns-Overall, a quarter of the sample ( $n=30,23$ percent) contained at least one of the seven identified concerns related to science or ethics. We found significant differences between general sources and science and health sources in the frequency of ethical issues. Of the general sources, a third ( $n=25,32$ percent) presented at least one issue; this was the case, however, in only a few ( $n=5,9$ percent) of the specialized science and health sources $\left(\chi^{2}=8.911, p=.003\right.$; Table 2$)$. Even though the small number does not permit statistical comparison on this aspect of press coverage, we found that six of the issues were more frequently found in general sources. Only the issue of validity occurred with

\footnotetext{
${ }^{3}$ One article out of 132 described research participation and recruitment without revealing the type of research involved.
} 
common frequency (see Table 4). When we grouped limitations, interpretation, and validity to analyze scientific issues broadly, this cluster occurred in twenty-four articles (18 percent).

The other concerns that are ethical in nature (human nature, confidentiality, troubling findings, and recruitment) appeared in nine articles ( 7 percent). We found scientific issues featured in eighteen of the general sources (23 percent) but only in five of the science and health literature ( 9 percent; $\chi^{2}=3.930, p=.047$ ). Ethical issues were present in only nine articles (11 percent) of the general sources and absent in the science and health literature $\left(\chi^{2}=6.480, p=.011\right.$; Table 2).

We also examined ethical and social concerns according to the type of research featured. We found that ethical issues were most frequent in articles that presented both health-related and non-health-related research (five of twenty-seven, 19 percent). Ethical concerns were featured in three of fifty-eight non-health-related articles (5 percent), and none were found in articles presenting only health-related research $\left(\chi^{2}=10.334, p=.006\right)$. Health-related benefits were found more often in articles that presented both types of research (nineteen of twenty-seven, 70 percent) than in articles presenting health-related research $(n=29,63$ percent $)$ or non-healthrelated research $\left(n=17,29\right.$ percent; $\left.\chi^{2}=17.536, p<.001\right)$. Non-health-related benefits were found significantly less often in health-related research $(n=1,2$ percent) than in non-healthrelated research $(n=11,19$ percent $)$ or articles presenting both types $\left(n=5,19\right.$ percent; $\chi^{2}=$ 7.330, $p=.026$; Table 3).

\section{Qualitative Analyses}

To enrich our understanding of the distribution and other quantitative characteristics of the data, we turn our attention now to qualitative features of the sample (see Table 4).

Limitations of the technology-We found references to the expression or appreciation of the limitations of the technology in nineteen of the articles (14 percent) in the sample. Three classes of limitations emerged:

1. Emphasis on the preliminary nature of findings or their limited generalizability by neuroimagers themselves (e.g., "It is far too early to take these findings as gospel" [Hall 1998, 22] and "Gabrieli warns to wait for further studies before putting too much faith in this one test" ["Study May Have Found Test" 1999])

2. Challenges to the basic assumption that levels of blood oxygenation are indicators of neuronal activity (e.g., "Increased blood flow, as shown in splotches of light, may not be an accurate surrogate for brain cell function" [Blakeslee 2000, 6])

3. Worries associated with the wider social usefulness of fMRI research and findings (e.g., "The results of experiments, undeniably exciting but nonetheless limited and preliminary, are being used by nonexperts to inform everything from the style of a mother's nurturing to the organization of day-care centers to public policy on child rearing, with precious little scientific data to support ambitious, even aggressive leaps into future education policy" [Hall 1998, 22])

Interpretation-We identified interpretation issues in ten of the articles (8 percent). Interpretation issues are reminiscent of limitations, but focus on the nature of the scientific and social conclusions drawn from the findings. We could further break down interpretation issues into two classes:

1. Technical and scientific issues, including the overinterpretation of results and concerns about statistical methods, many of which related specifically to the possibility of correlating brain activation to neurocognitive function (e.g., "Just 
because an area of a patient's brain 'lights up' during an fMRI scan doesn't mean it's the seat of the behaviour being studied" [Spinney 2002, 38])

2. Social interpretation issues, including the wider meaning of fMRI findings in the public arena (e.g., "When the results . . come out, they are bound to cause a stirand they are also bound to be misinterpreted" [Hall 1998, 22])

Validity—Like limitations and interpretation issues, validity issues are also tightly interwoven in the technical and scientific aspects of fMRI. Validity issues, highlighted in eight of the articles (6 percent) in the sample, focused on the risks of and concerns about poor scientific research design or lack of standardized practice. For example, "That is an example of a bad imaging experiment. ... scientifically, it tells you nothing. The study suffers from a lack of theoretical context ... we don't have a theory of what it takes to make a moral judgment" (Monasterky 2001, 20). Some questioned the validity of fMRI research itself more broadly: "There is nothing particularly interesting coming out of imaging" and "imaging studies that purport to find localization of mental abilities in the brain suffer from a number of flaws that invalidate such discoveries" (Monasterky 2001, 20).

Human nature-We found references to issues bearing on human nature in six of the articles ( 5 percent) in the sample. Most of these related to neuromarketing (i.e., possible misuses in the study of consumer preferences and its corollary implications of reducing persons to means): "It raises serious philosophical questions, because it reduces us to a machine" (Sample and Adam 2003, 4) and "it's wrong to use a medical technology for marketing, not healing" (Hamilton 2004, 78). Other examples related to misuses of fMRI as a surveillance technique:

Like a fingerprint ... the brain is always there, storing a record of the actions and even the thoughts involved in our actions. No matter how cleverly we might try to deceive, in the future, our brains could be used as evidence against us. (Persaud 2001, 21)

Other ethical issues-We also infrequently found other ethical issues, such as confidentiality and privacy issues, troubling findings, and the protection of human subjects enrolled in research. Thought privacy was a significant theme, because the nature of fMRI findings may reveal private and personal information on neurocognitive processes. For example,

The suggestion that brain scans could reveal not just our future health, but the intricacies of our personalities and how we might behave in a given situation is unsettling enough to some scientists that they want legislation to stop brain-scan records falling into the wrong hands. (Sample and Adam 2003, 4)

Troubling findings involved clinical findings detected unexpectedly in the research setting. For example,

Very occasionally, the structural scans of volunteers in research projects do reveal tumours. And as a researcher, rather than clinician, [name of investigator] is not allowed to break bad news. 'I tell them the scan hasn't worked properly and I can't show them it,' he says. 'And then I contact their GP [general practitioner] and tell them to arrange a medical scan."” (Adam 2003, 5)

\section{Discussion}

Our analysis of coverage of fMRI in the print media suggests an overall optimism for this frontier neurotechnology that is especially marked in reports originating from specialized news 
sources. Overall, clinical research is presented more optimistically than nonclinical research, and scientific concerns are featured more often than ethical ones. The qualitative data further show that scientific issues include both technical and social concerns and outweigh ethical issues in sheer numbers.

No doubt, limitations are inherent to our search strategies and the LexisNexis Academic database itself, and small numbers in certain areas limit the depth of the present analysis. Certainly, more research is needed to fully understand how the ethical issues of emerging neurotechnologies are discussed in the press. Nonetheless, this exploratory study yielded powerful insights into the portrayal of this technology by the press.

\section{Improving Health or Unraveling Mysteries of the Mind?}

The results of our study suggest that press coverage is greater for studies of non-health-related phenomena, in particular higher order cognition, emotion, and social behaviors studies. However, even if such research is more frequent in number, health benefits are emphasized most. This suggests that the depiction of fMRI as a health technology is unrelenting, even if non-health-related research is the prevailing focus. The interpretation of this disequilibrium is open. Because structural magnetic resonance imaging, as the precursor to fMRI, was realized initially as a clinical tool, the portrayal of the health benefits of the technology could simply be a natural segue from the known historical uses of imaging methods (Lentle and Aldrich 1997). We noted, however, that the treatment of disease is the most frequently featured benefit, even though diagnosis and monitoring more appropriately define the likely contributions of fMRI to health care (Desmond and Chen 2002; Mazziotta 2000).

A competing interpretation is that health content may be used to facilitate social acceptance of fMRI. Conrad (2001) suggested that researchers have an interest in promoting the benefits from their research to gather support, and health benefits are undoubtedly one of the most appreciated outcomes of scientific research and biotechnology. In keeping with this alternative explanation, we note that reporting of health-related research is less critical than reporting of its non-health-related counterpart. Even if our study does not provide data that informs us about motivations, we also note corresponding differences in terms of tone and presence of ethical issues.

A third possible interpretation of the disequilibrium is that while the reporting of health research tends to promote optimism on the part of readers, the reporting of non-health-related research can elicit skepticism. For example, neuromarketing studies or possible truth-technology improvements received a fair deal of critical attention in our sample of print media. This tendency corresponds to debates taking place in highly visible peer-reviewed journals in the neuroscience literature ("Brain Scam?" 2004; "Does Neuroscience Threaten Human Values?" 1998; Hoag 2003; Jaffe 2004; "Silence of the Neuroengineers" 2003). In fact, the journey of fMRI to the social domain appears to be in large part fueling ethical discussions in the media. We have suggested, in fact, that senses of neurorealism, neuroessentialism, and neuropolicy are commonly conveyed in media coverage of fMRI (Racine, Bar-Ilan, and Illes 2005). More precisely, fMRI seems to imply visual proof of the fundamental nature of reality and subjectivity, which propels the use of fMRI findings in policy making. Such powerful representations are bound to bring reactions from the public and the scientific community, especially when the applications are provocative.

In addition to this evidence, previous press studies of genomics have reported that the media preferentially cover high-profile examples of scientific attempts or progress, such as human cloning, rather than potentially more mundane ethical issues, such as those associated with clinical applications of genetic testing and screening (Geller, Bernhardt, and Holtzman 2002). Another study has shown that more than one-third of articles dealing with genomics present 
ethical issues. This proportion increases when other biotechnological sectors, especially controversial ones such as stem-cell research, reproductive cloning, or new reproductive technologies, figure in the articles (Racine et al. 2006). This may be consistent with increased pressures for fast journalism and highly visible stories (Gardner, Csikszentmihalyi, and Damon 2001; Nelkin 1995). Unfortunately, the downside of this dynamic is that it can overshadow relevant ethical issues related to less spectacular health care applications of fMRI.

Consequently, many important and pressing neuroethical issues, such as the use of fMRI for the early diagnosis of late-onset diseases (Rosen et al. 2002), are left unattended. Even if they are of great public interest and may affect people's lives directly, these go practically unnoticed in our sample.

\section{Unattended Ethical Controversies}

We observed that the majority of articles were uncritical of fMRI. Other press studies of research such as genomics and genetics and biotechnologies have frequently observed similar optimistic reporting (Conrad 2001; Kohring and Matthes 2002; Moreno, Lujan, and Moreno 1996; Mulkay 1994; Priest and Talbert 1994; Racine et al. 2006). A small number of media reports are highly critical (Conrad 2001; Moreno, Lujan, and Moreno 1996; Racine et al. 2006). Reporting of fMRI conforms to the majority of these patterns and further illustrates how the expectation of balanced scientific reporting (Rose 2003; Thompson and Nelson 2001) can collide with the social demand for research.

In contrast to the optimism for fMRI research, we did find substantial content related to specific scientific and ethical concerns. The presence of ethical issues in fMRI reporting is still lower, however, than media coverage of genomics and genetics, for which figures around 40 percent have been identified in the general press (Conrad 2001; Craig 2000; Petersen 2001; Racine et al. 2006). Although there are differences in the samples, this comparison sustains the point of view that the issues of neuroscience have not yet been brought to the public eye as frequently as issues of genomics (Illes and Racine 2005; Wolpe 2002). One explanation for this phenomenon may lie in the legacy of eugenics and discrimination in genetics, which still has a significant impact on public understanding of genetics (Geller, Bernhardt, and Holtzman 2002). A second explanation bears on the vast interdisciplinary research networks that have been supported by funding agencies to investigate the ethical, legal, and social issues of genomics. These scholarly activities contribute to the sustained attention to risks and concerns related to genomics. Equivalent institutional support of this nature does not yet exist for the ethics of contemporary neuroscience. Nonetheless, the overall lesser attention to these issues in fMRI research and maybe more broadly to neuroscience remains an interesting puzzle in the communication of the ethical dimensions of science. Why have the issues of neuroscience gone largely unnoticed in comparison with genomics?

\section{Communicating with Specialized and Lay Audiences}

Our data indicate that specialized sources are less critical of fMRI than general sources. This suggests that ethical discussion is taking place in the public domain and that scientists are brought to discuss these issues in wider forums rather than in specialized ones. The same observation applies to scientific issues. The reasons for the differences, however, are unclear. One possible explanation is that specialized science and medical magazines are geared to showcase technology. To be fair, there has also been some ethical discussion within the neuroscience community concerning, for example, the use of functional neuroimaging markers as a diagnostic tool (Desmond and Chen 2002; Rosen et al. 2002) or the extension of neuroimaging to social behavior ("Brain Scam?" 2004; Jaffe 2004). However, the increasing advances in neuroscience merit broader discussion. 
Researcher responsibility is also called on by the fact that two-thirds of articles presented no explanation of what fMRI achieves technically. A Brazilian survey of "neuroscience literacy" showed that the public is uninformed about major research methodologies such as electroencephalography, positron emission tomography, and fMRI (Herculano-Houzel 2002). Many researchers and scholars have voiced concerns that simplistic understanding of such neuroimaging modalities may increase the risk for misuse and the possibility of the abuse of consumers who are lured by the high-tech profile of the technology (Farah and Wolpe 2004; Gura 2005; Hinton 2002; Kulynych 2002; Stufflebaum and Bechtel 1997). Our study, therefore, further grounds repeated calls for increased neuroscientist involvement in the popularization of research findings (Bruer 1998; DiPietro 2000; Hall, Carter, and Morley 2004; Hinton 2002; Kulynych 2002; Racine, Bar-Ilan, and Illes 2005; Rose 2003), as well as particular attention to the epistemological issues of neuroimaging in public communication (Illes and Racine 2005; Illes, Racine, and Kirschen 2005).

\section{Scientific and Manifest Images: A Philosophical Dilemma}

We noticed that scientific issues such as limitations, interpretation, and validity are doubleheaded, because they include both technical and social concerns. Technical concerns are mostly reported with the aim of presenting qualified results. However, we observed deeper debate within the scientific community, especially when researchers question the assumptions underlying fMRI or criticize colleagues for not taking into account the limits of their findings. Social concerns occur when results are invested with broader cultural meaning that can lead to social tensions (Racine, Bar-Ilan, and Illes 2005).

We may analyze the interaction between scientific dimensions of these issues and their wider social depiction following philosopher Wilfred Sellars (1963), who distinguished the "manifest" and the "scientific" views of the world. The manifest image of the world is the common view of humans. It is the way we see ourselves in ordinary life on the basis of free will and other cultural assumptions. Exploring the structure of the manifest image is largely the concern of the humanities, even though this is changing with the advent of social neuroscience (Cacioppo et al. 2000). The scientific image of the world is the scientific view of ourselves. This scientific image can put in question the manifest image and beliefs underlying it, such as free will and responsibility. While neuroscience studies of moral emotions and cooperation, for example, are in many ways enriching our scientific view of the world, some may interpret this trend as an impoverishment or a threat ("Does Neuroscience Threaten Human Values?" 1998) to our manifest image of the world (i.e., our common view of human phenomena on the basis of existing human cultures).

A parallel can be drawn here with the concept of geneticization, which was used to criticize the uncritical acceptance of health framed predominantly in the language of genetics (Lippman 1991, 1992). Our data suggest that a similar phenomenon of biologization could occur in neuroscience. Researchers engaged in affective neuroscience (Dalgleish 2004), social neuroscience, and neurophilosophy (Churchland 2002) are exploring new interactions between neuroscience and the social sciences and the humanities. Hence, concerns over biologization could easily increase if the manifest image is depicted in media as being jeopardized by the new neuroscientific image. We predict that this turn in the potential impact of neuroscience will surface as a key challenge in science communication.

\section{Conclusion}

The results of this study indicate that fMRI reporting follows general patterns observed in past reporting of genomics and biotechnologies. Disequilibrium between coverage of non-healthrelated research and clinical benefits suggests that non-health-related research is galvanizing the ethical debates surrounding neuroimaging. Analysis of the scientific issues indicates that 
neuroscience may bring concerns of biologization of thought and culture to the public foreground.

Given that the scientific complexity of the brain is overwhelming and, as we suggest, that its social meaning is part of a wider debate, approaches to science communication will need to be informed accordingly. In this respect, neuroscience can be a model for further exploring principles of multicultural communication (van Dijck 2003) and mechanisms that foster open science communication. From the public's point of view, when research results are publicized and concern personality and concepts related to self-identity, they are bound to interact with the various cultural, religious, and secular sources of our self-identity (Taylor 1989). Broad interdisciplinary and public dialogue is an essential element, therefore, in ensuring the responsible communication and social impact of neuroscience.

\section{References}

Adam D. I feel as if I've been entombed: Getting your head examined. The Guardian 2003 November $20 ;: 5$.

Anderson MC, Ochsner KN, Kuhl B, Cooper J, Robertson E, Gabrieli SW, Glover GH, Gabrieli JDE. Neural systems underlying the suppression of unwanted memories. Science 2004;303(5655):232-35. [PubMed: 14716015]

Blakeslee S. Just what's going on inside that head of yours? The New York Times 2000 March 14;:6.

Brain scam? Nature Neuroscience 2004;7(7):683.

Bruer JT. The brain and child development: Time for some critical thinking. Public Health Reports 1998;113(5):388-98. [PubMed: 9769763]

Cacioppo JT, Berntson GG, Sheridan JF, McClintock MK. Multi-level integrative analyses of human behavior: Social neuroscience and the complementing nature of social and biological approaches. Psychological Bulletin 2000;126(6):829-43. [PubMed: 11107878]

Cardinal, G.; Deschênes, M.; Knoppers, BM.; Hudson, T.; Labuda, D.; Bouchard, G.; Racine, E.; Fecteau, C.; Truong, S.; Laberge, C. Statement of principles on the ethical conduct of human genetic research involving populations. 2003. http://www.rmga.qc.ca/doc/pop/statement_ANG_.pdf

Churchland, PS. Brain-wise: Studies in neurophilosophy. Cambridge, MA: MIT Press; 2002.

Condit CM. What is "public opinion” about genetics? Nature Reviews Genetics 2001;2:811-15.

Condit, CM.; Parrott, RL.; O'Grady, B. Principles and practices of communication processes for genetics in public health. In: Koury, MJ.; Burke, W.; Thomson, EJ., editors. Genetics and public health in the 21 st century: Using genetic information to improve health and prevent disease. Oxford, UK: Oxford University Press; 2000.

Conrad P. Genetic optimism: Framing genes and mental illness in the news. Culture, Medicine, and Psychiatry 2001;25(2):225-47.

Conrad P, Gabe J. Introduction: Sociological perspectives on the new genetics: An overview. Sociology of Health \& Illness 1999;21(5):505-16.

Craig DA. Ethical language and themes in news coverage of genetic testing. Journalism and Mass Communication Quarterly 2000;77(1):160-74.

Dalgleish T. The emotional brain. Nature Reviews Neuroscience 2004;5(7):582-89.

Desmond JE, Chen SHA. Ethical issues in the clinical application of fMRI: Factors affecting the validity and interpretation of activations. Brain and Cognition 2002;50(3):482-97. [PubMed: 12480492]

DiPietro JA. Baby and the brain: Advances in child development. Annual Review of Public Health 2000;21:455-71.

Does neuroscience threaten human values? Nature Neuroscience 1998;1(7):535-36.

Farah MJ, Wolpe PR. Monitoring and manipulating brain function: New neuroscience technologies and their ethical implications. Hastings Center Report 2004;34(3):35-45. [PubMed: 15281725]

Farwell LA, Smith SS. Using brain MERMER testing to detect concealed knowledge despite efforts to conceal. Journal of Forensic Sciences 2001;46(1):1-9. 
Feinstein AR, Cicchetti D. High agreement but low kappa: I. The problems of two paradoxes. Journal of Clinical Epidemiology 1990;43(6):543-49. [PubMed: 2348207]

Gardner, H.; Csikszentmihalyi, M.; Damon, W. Good work: When excellence and ethics meet. New York: Basic Books; 2001.

Geller G, Bernhardt BA, Holtzman NA. The media and the public reaction to genetic research. JAMA 2002;287:773. [PubMed: 11851549]

Greely, HT. Neuroethics and ELSI: Some comparisons and considerations; Neuroethics: Mapping the Field; San Francisco, CA. 2002. Presented at

Gura T. Big plans for little brains. Nature 2005;435(7046):1156-58. [PubMed: 15988491]

Hall SS. The scientific method: Test-tube moms. The New York Times 1998 April 5;:22.

Hall W, Carter L, Morley KI. Neuroscience research on the addictions: A prospectus for future ethical and policy analysis. Addictive Behaviors 2004;29(7):1481-95. [PubMed: 15345277]

Hamilton JO. Journey to the center of the mind. BusinessWeek 2004 April 19;:78.

Herculano-Houzel S. Do you know your brain? A survey on public neuroscience literacy at the closing of the decade of the brain. Neuroscientist 2002;8(2):98-110. [PubMed: 11954564]

Hinton VJ. Ethics of neuroimaging in pediatric development. Brain and Cognition 2002;50(3):455-68. [PubMed: 12480490]

Hoag H. Neuroengineering: Remote control. Nature 2003;423(6942):796-98. [PubMed: 12815397]

Illes J, Kirschen MP, Gabrieli JD. From neuroimaging to neuroethics. Nature Neuroscience 2003;6(3): 205.

Illes J, Racine E. Imaging or imagining? A neuroethics challenge informed by genetics. American Journal of Bioethics 2005;5(2):5-18. [PubMed: 16036688]

Illes, J.; Racine, E.; Kirschen, M. A picture is worth 1000 words, but which 1000 ? In Neuroethics: Defining the issues in theory, practice and policy. Illes, J., editor. Oxford, UK: Oxford University Press; 2005.

Illes J, Raffin TA. Neuroethics: An emerging new discipline in the study of brain and cognition. Brain and Cognition 2002;50(3):341-44. [PubMed: 12480481]

Izzetoglu, K.; Bunce, S.; Izzetoglu, M.; Onaral, B.; Pourrezaei, K. Functional near-infrared neuroimaging; The 26th annual international conference of the IEEE Engineering in Medicine and Biology Society; San Francisco, CA. 2004. Presented at

Jaffe S. Fake method for research impartiality (fMRI). The Scientist 2004 July 19;:64.

Kennedy, D. Neuroethics: An uncertain future; The annual meeting of the Society for Neuroscience; New Orleans, LA. November 10; 2003. Presented at

Kohring M, Matthes J. The face $(\mathrm{t}) \mathrm{s}$ of biotech in the nineties: How the German press framed modern biotechnology. Public Understanding of Science 2002;11(2):143-54. [PubMed: 14621677]

Kulynych J. Legal and ethical issues in neuroimaging research: Human subjects protection, medical privacy, and the public communication of research results. Brain and Cognition 2002;50(3):345-57. [PubMed: 12480482]

Langleben DD, Schroeder L, Maldjian JA, Gur RC, McDonald S, Ragland JD, O’Brien CP, Childress AR. Brain activity during simulated deception: An event-related functional magnetic resonance study. NeuroImage 2002;15(3):727-32. [PubMed: 11848716]

Lentle B, Aldrich J. Radiological sciences, past and present. The Lancet 1997;350(9073):280-85.

Lippman A. Prenatal genetic testing and screening: Constructing needs and reinforcing inequalities. American Journal of Law and Medicine 1991;17(12):15-50. [PubMed: 1877608]

Lippman A. Led (astray) by genetic maps: The cartography of the human genome and health care. Social Science and Medicine 1992;35(12):1469-76. [PubMed: 1485194]

Mauron A. Renovating the house of being. Annals of the New York Academy of Science 2003;1001:24052.

Mazziotta JC. Window on the brain. Archives of Neurology 2000;57(10):1413-21. [PubMed: 11030792]

Monasterky R. Land mines in the world of mental maps. Chronicle of Higher Education 2001 November $2 ;: 20$. 
Moreno, C.; Lujan, J.; Moreno, L. La ingeniera genética humana en la prensa: Analísis de contenido de ABC, El Pais y La Vanguardia (1988-1993). Madrid, Spain: Instituto de Estudios Avanzados (CSIC); 1996.

Moreno JD. Neuroethics: An agenda for neuroscience and society. Nature Reviews Neuroscience 2003;4 (2):149-53.

Mulkay M. Embryos in the news. Public Understanding of Science 1994;3(1):33-51. [PubMed: 11659866]

Nelkin, D. Selling science: How the press covers science and technology. Rev. New York: W. H. Freeman; 1995.

Neuendorf, KA. The content analysis guidebook. Thousand Oaks, CA: Sage; 2002.

Open your mind. 2002. The Economist May 25.

People v. Weinstein (591 NYS 2d 715) (Sup. Ct. 1992).

Persaud R. Who's telling porkies about racism? Refinements in brain-scanning could soon make the thought police a reality. The Daily Telegraph 2001 April 25;:21.

Petersen A. Biofantasies: Genetics and medicine in the print news media. Social Science and Medicine 2001;52(8):1255-68. [PubMed: 11281408]

Priest SH, Talbert J. Mass media and the ultimate technological fix: Newspaper coverage of biotechnology. Southwestern Mass Communication Journal 1994;10(1):76-85.

Racine E. Discourse ethics as an ethics of responsibility: Comparison and evaluation of citizen involvement in population genomics. Journal of Law, Medicine \& Ethics 2003;31(3):390-97.

Racine E, Bar-Ilan O, Illes J. fMRI in the public eye. Nature Reviews Neuroscience 2005;6(2):159-64.

Racine E, Gareau I, Doucet H, Jobin G, Laudy D, Jobin G, Schraedley-Desmond P. Hyped biomedical science or uncritical reporting? Press coverage of genomics (1992-2001) in Québec. Social Science \& Medicine 2006;62(5):1278-90. [PubMed: 16174544]

Raichle, M. Neuroethics: Emerging ethical issues in neuroscience; The annual meeting of the Society for Neuroscience; San Diego, CA. October 27; 2004. Presented at

Rose SPR. How to (or not to) communicate science. Biochemical Society Transactions 2003;31(2):30712. [PubMed: 12653626]

Rosen AC, Bodke ALW, Pearl A, Yesavage JA. Ethical and practical issues in applying functional imaging to the clinical management of Alzheimer's disease. Brain and Cognition 2002;50(3):498 519. [PubMed: 12480493]

Roskies A. Neuroethics for the new millennium. Neuron 2002;35(1):21-23. [PubMed: 12123605]

Ross P. Mind readers. Scientific American 2003 September;:74-77. [PubMed: 12951830]

Sample I, Adam D. The brain can't lie: Brain scans reveal how you think and feel and even how you might behave. The Guardian 2003 November 20;:4.

Schacter DL, Buckner RL, Koutstaal W. Memory, consciousness and neuroimaging. Philosophical Transactions of the Royal Society of London B 1998;353:1861-1978.

Sellars, W. Science, perception, and reality. New York: Humanities Press; 1963.

Silence of the neuroengineers. Nature 2003;423:787.

Spinney L. The mind readers. New Scientist 2002 September $21 ;: 38$.

Study may have found test to scientifically diagnose ADHD. LRP Publications; 1999 Feb.

Stufflebaum RS, Bechtel W. PET: Exploring the myth and the method. Philosophy of Science 1997;64 (Suppl):S95-106.

Taylor, C. Sources of the self: The making of modern identity. Cambridge, MA: Harvard University Press; 1989.

Thompson RA, Nelson CA. Developmental science and the media. American Psychologist 2001;56(1): 5-15. [PubMed: 11242988]

2003 Japan Prizes on fMRI, chaos, fractals. The Daily Yomiuri 2003 January 15;:10.

van Dijck J. After the "two cultures": Toward a "(multi)cultural" practice of science communication. Science Communication 2003;25:177-90.

Williams C, Kitzinger J, Henderson L. Envisaging the embryo in stem cell research: Rhetorical strategies and media reporting of the ethical debates. Sociology of Health \& Illness 2003;25(7):793-814. 
Wolpe PR. The neuroscience revolution. The Hastings Center Report 2002;32(4):8. [PubMed: 12362529]

\section{Biographies}

Eric Racine is director of the Neuroethics Research Unit at the Institut de Recherches Cliniques de Montréal. Previously, he was a postdoctoral fellow in the Program in Neuroethics at the Center for Biomedical Ethics, Stanford University.

Ofek Bar-Ilan holds a bachelor of science degree in biology from the Dominican University of California. Previously, she was a research assistant in the Program in Neuroethics at the Center for Biomedical Ethics, Stanford University.

Judy Illes is the director of the Program in Neuroethics and a senior research scholar at Stanford University, where she holds a joint appointment in the Stanford Center for Biomedical Ethics and the Department of Radiology. 
Coding Structure and Reliability

Table 1

\begin{tabular}{|c|c|c|c|}
\hline Code & Subcode & Definition & Reliability $^{a}$ \\
\hline \multirow[t]{5}{*}{ Target cohort } & Infants & Stated or individuals aged under three & 100 \\
\hline & $\begin{array}{l}\text { School aged or } \\
\text { adolescents }\end{array}$ & Stated or individuals aged between three and seventeen & 92 \\
\hline & Adults & Stated or individuals aged between eighteen and sixty-five & 100 \\
\hline & Aging & Stated or individuals aged over sixty-five & 100 \\
\hline & Animals & Research done on animals & 88 \\
\hline \multirow[t]{2}{*}{ Explanation of fMRI } & Simplified ${ }^{b}$ & $\begin{array}{l}\text { Article includes some technical details about fMRI (less than two } \\
\text { sentences) }\end{array}$ & 84 \\
\hline & Detailed $^{b}$ & $\begin{array}{l}\text { Article includes extensive technical details about the mechanics of } \\
\text { fMRI (more than two sentences) }\end{array}$ & 96 \\
\hline \multirow[t]{2}{*}{ Research } & Health-related ${ }^{c}$ & Research is performed on disease mechanisms or treatments & 84 \\
\hline & Non-health-related ${ }^{c}$ & $\begin{array}{l}\text { Research is performed without the aim of obtaining insights on } \\
\text { disease mechanisms or treatments (e.g., fundamental brain } \\
\text { processes and systems) }\end{array}$ & 88 \\
\hline \multirow[t]{2}{*}{ Prospects } & Health-related ${ }^{c}$ & $\begin{array}{l}\text { Prospects of study and benefits of study to improve health either } \\
\text { in preventing disease or improving treatments or cures }\end{array}$ & 76 \\
\hline & Non-health-related ${ }^{c}$ & $\begin{array}{l}\text { Prospects of study and benefits of study are not related to health } \\
\text { improvement }\end{array}$ & 88 \\
\hline \multirow[t]{3}{*}{ Tone } & Uncritical $^{b}$ & Article presents no risks & 100 \\
\hline & Balanced $^{b}$ & $\begin{array}{l}\text { Article presents as many benefits concerning fMRI as it does risks; } \\
\text { pros and cons of fMRI are presented }\end{array}$ & 100 \\
\hline & $\mathrm{Critical}^{b}$ & Article presents more risks associated with fMRI than benefits & 100 \\
\hline \multirow[t]{2}{*}{ Issues } & Scientific $^{d}$ & $\begin{array}{l}\text { Potential harms and risks of neurotechnology from scientific and } \\
\text { medical standpoints }\end{array}$ & $100^{e}$ \\
\hline & Ethical $^{d}$ & $\begin{array}{l}\text { Potential harms and risks of fMRI from ethical, social, and legal } \\
\text { standpoints }\end{array}$ & $100^{f}$ \\
\hline
\end{tabular}

Note: $\mathrm{fMRI}=$ functional magnetic resonance imaging.

${ }^{a}$ Percentage agreement. One code identifying the diffusion of fMRI technology was discarded because of low reliability.

${ }^{b}$ Mutually exclusive subcodes.

${ }^{c}$ Further analyzed to identify specific areas of research or application.

${ }^{d}$ Code further analyzed for qualitative features. See Table 4 for definitions.

${ }^{e}$ Includes the following subcodes, each with 100 percent agreement: limitations, interpretation, and validity. See Table 4 for definitions.

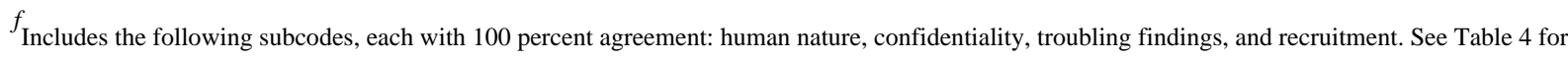
definitions. 
Table 2

Tone and Concerns Identified in General and Specialized News Sources (in percentages)

\begin{tabular}{lccc}
\hline Code & Sample & General Sources & Specialized Sources \\
\hline Tone & & & 89 \\
$\quad$ Uncritical & 79 & 22 & 8 \\
Balanced & 16 & 6 & 4 \\
$\quad$ Critical & 5 & 32 & 9 \\
Issues & 23 & 23 & 9 \\
$\quad$ At least one issue & 18 & 11 & 0 \\
Scientific issue & 9 & & \\
Ethical issue & & & \\
\hline
\end{tabular}


Table 3

Tone and Concerns Identified in Press Coverage of Health and Non-Health-Related Research (in percentages)

\begin{tabular}{|c|c|c|c|}
\hline Code & Health-Related Research & Non-Health-Related Research & Both \\
\hline \multicolumn{4}{|l|}{ Tone } \\
\hline Uncritical & 91 & 78 & 63 \\
\hline Balanced & 9 & 14 & 30 \\
\hline Critical & 0 & 9 & 7 \\
\hline \multicolumn{4}{|l|}{ Issues } \\
\hline At least one issue & 9 & 24 & 41 \\
\hline Scientific issue & 9 & 21 & 30 \\
\hline Ethical issue & 0 & 5 & 19 \\
\hline \multicolumn{4}{|l|}{ Benefits } \\
\hline Health benefit & 63 & 29 & 70 \\
\hline Non-health-related benefit & 2 & 19 & 19 \\
\hline
\end{tabular}


Table 4

Qualitative Features of the Press Coverage Sample (in percentages)

\begin{tabular}{|c|c|c|c|c|}
\hline Issue & Description & Sample & General Sources & Specialized Sources \\
\hline Limitations & $\begin{array}{l}\text { Risks and concerns related to the } \\
\text { limitations of knowledge gained by fMRI }\end{array}$ & 14 & 19 & 8 \\
\hline Interpretation & $\begin{array}{l}\text { Risks and concerns related to } \\
\text { interpretation/meaning of findings by the } \\
\text { public and researchers }\end{array}$ & 8 & 10 & 4 \\
\hline Validity & $\begin{array}{l}\text { Risks and concerns related to scientific } \\
\text { research design }\end{array}$ & 6 & 6 & 6 \\
\hline Human nature & $\begin{array}{l}\text { Risks and concerns related to } \\
\text { transformation of human nature } \\
\text { conducing to see humans as mere means, } \\
\text { misuses }\end{array}$ & 5 & 8 & 0 \\
\hline Confidentiality & $\begin{array}{l}\text { Risks and concerns related to potential } \\
\text { harms due to sharing of confidential } \\
\text { information }\end{array}$ & 2 & 4 & 0 \\
\hline Troubling findings & $\begin{array}{l}\text { Risks and concerns related to potential } \\
\text { individual or social harms of findings }\end{array}$ & 2 & 4 & 0 \\
\hline Recruitment & $\begin{array}{l}\text { Risks and concerns related to recruitment } \\
\text { of research subjects, protection of } \\
\text { subjects enrolled in protocols }\end{array}$ & 1 & 1 & 0 \\
\hline
\end{tabular}

Note: $\mathrm{fMRI}=$ functional magnetic resonance imaging. 